\title{
Similar antibody response observed in single-dose-vaccination vs. revaccination against Aujeszky's disease in wild boar
}

\author{
D. RISCO, P. GONÇALVES, R. CERRATO, P. FERNÁNDEZ-LLARIO
}

Affiliation: Innovación en Gestión y Conservación de Ungulados S. L. C / San Pedro de Alcántara 14 2A, CP 10001, Cáceres, Spain

Received February 13, 2018; revised March 2, 2018; accepted October 10, 2018

\begin{abstract}
Summary. - Wild boar is an important reservoir of Aujeszky's disease virus (ADV). There is concern that transmission of this virus from wild boar to domestic pigs is possible. The aim of this work was to compare the antibody response produced by single dose of a gE-deleted ADV vaccine in wild boar to revaccinated animals, to assess if simple single-dose vaccination plans should be examined as a possible control measure against ADV in wild boar. Twenty-five wild boar (ages ranging between 2.5 to 5 months) were included in this study and distributed in three different groups: a control group $(n=5)$, a single-dose group (10 animals vaccinated only with one dose (day 0$)$ ) and a revaccinated group [10 animals vaccinated (day 0 ) and revaccinated (day 28)]. Mean antibody titers against ADV were determined in three groups using an ELISA assay at three different time points [day 0 (pre-vaccination), 28 (post $1^{\text {st }}$ dose) and 56 (post $2^{\text {nd }}$ dose)]. At day 28 , single-dose and revaccinated groups showed a significant increment of antibody titers whereas antibodies in the control group remained stable. At day 56, revaccinated animals did not show a significant increment and antibody titers were similar to those found in animals vaccinated with one dose. These results indicate that vaccination with one dose produces a similar early antibody response to revaccination and therefore, should be examined as a possible control measure against ADV in wild boar.
\end{abstract}

Keywords: Aujeszky's disease; serology; vaccination; wild boar

Aujeszky's disease (AD) is a viral disease with a strong economic impact on the pig industry (Mettenleiter et al., 2012). In recent decades, many countries have developed official eradication programs against $\mathrm{AD}$, achieving a drastic reduction of the prevalence in pigs from many countries (e.g. Spain), or even, the complete eradication (e.g. Germany, Netherland, France) (Müller et al., 2011).

In these countries, the wild boar, which may act as an important wild reservoir of Aujeszky's disease virus (ADV), poses a risk of transmission of ADV to domestic pigs (Müller et al., 2011). For example, in Spain, the prevalence of $\mathrm{AD}$ in wild boar populations has risen in recent decades, ranging between $40-80 \%$ in different populations (Boadella

*E-mail: driscope@gmail.com; phone: +34-662021137. Abbreviations: $\mathrm{AD}=$ Aujeszky's disease; $\mathrm{ADV}=\mathrm{AD}$ virus; $\mathrm{gE}=$ glycoprotein $\mathrm{E} ; \mathrm{gB}=$ glycoprotein $\mathrm{B}(\mathrm{gB})$ et al., 2012). The wild boar could pose an epidemiological risk mainly in areas with outdoor pig farms, where direct contact between domestic pigs and this wild species is more likely (Koppel et al., 2007). In fact, sporadic AD outbreaks declared in domestic pigs from $\mathrm{AD}$-free areas have been attributed to the presence of wild boar infected with this virus (Bronner et al., 2010).

Because of the importance of the wild boar as a reservoir of ADV, control measures to reduce the risk of transmission of this virus to domestic pigs are being explored (Maresch et al., 2012). Vaccination and revaccination with gE-deleted vaccines has been proven to produce a serological response against ADV in the wild boar (Ruiz-Fons et al., 2008), suggesting it could be an effective measure. However, vaccination programs based on repetitive revaccinations are not reliable in most wild boar estates due challenges of wild boar management. Therefore, more simple vaccination programs (perhaps using only single-dose vaccination) could be considered for implementation on wild boar estates. 
The aim of this work was to compare the serological response produced by gE-deleted ADV vaccine in wild boar vaccinated with one dose and animals revaccinated with a second dose, in order to assess if a simple single-dose vaccination plan should be further studied as a possible control measure against $\mathrm{AD}$ in wild boar.

The study was carried out at a game estate located in Azuaga (Extremadura, south-western Spain). This estate is bounded by a fence enclosing about 700 ha. Supplementary food (mainly fodder) is provided to wild boar daily in twelve feeders strategically distributed throughout the estate. All of these feeders are surrounded by a fence with gates of different size allowing selection of the size of the animals that will be fed. In addition, these gates are provided with a block system allowing the entrance of animals but not the escape when activated, acting as a selective feeding trap.

On the $8^{\text {th }}$ of July in 2014 (day 0 of the experiment), 25 wild boar of ages ranging from 2.5 to 5 months were captured using four of the feeding-traps located on the estate. These animals were individually identified with an electronic microchip, which was injected just behind their left ears, and transported to a conditioned area on the estate where the experiment was carried out. This experimental area is composed of a building of $200 \mathrm{~m}^{2}$ that was provided with feeders and water troughs to supply food and water to studied animals. In addition, this building had a system of coordinated doors and a management area allowing the containment of the animals to be vaccinated, examined or sampled.

Three groups of animals were randomly generated using the 25 captured wild boar: a control group of 5 animals, which received two doses of placebo (physiologic saline solution) at day 0 and at day 28 ( $5^{\text {th }}$ August 2014) of the experiment; a single-dose vaccinated group of 10 animals, which were vaccinated intramuscularly with a commercial gE-deleted attenuated vaccine against ADV (Syvajeszky, Syva, Spain) at day 0 of the experiment and injected with a placebo at day 28; and finally, a revaccinated group of 10 animals, which were vaccinated intramuscularly with the same commercial attenuated $\mathrm{ADV}$ vaccine twice (at day 0 and at day 28).

Blood samples from all of these animals were taken by puncturing the ophthalmic sinus at three different timepoints during the experiment: day 0 (just before the first dose of vaccine or placebo), day 28 (just before the second dose of vaccine or placebo) and day 56 ( $2^{\text {nd }}$ September of 2014). On this latest date, all the animals were released to their original habitat. Extracted blood samples were kept at $4^{\circ} \mathrm{C}$ until they were centrifuged at 3,500 rpm for five minutes within the first $24 \mathrm{~h}$ after sampling. These sera were then extracted and stored at $-20^{\circ} \mathrm{C}$ until their utilization.

A commercial indirect ELISA assay (INGEZIM ADV TOTAL, INGENASA, Spain) was used to detect antibodies against glycoprotein $\mathrm{B}(\mathrm{gB})$ of $\mathrm{ADV}$ in collected sera. This assay was carried out following manufacturer's recommendations allowing the estimation of anti-gB antibody titers in all the studied animals at each time-point of the experiment. Different statistical tests were used to compare anti-gB antibody titers found in the three different groups of animals at each time-point (day 0, day 28 and day 56) (Kruskal Wallis test); and variations in anti-gB antibody titers in each group post $1^{\text {st }}$ dose, post $2^{\text {nd }}$ dose and throughout the experiment (t-test for paired samples). Furthermore, we explored the correlation between the increment of anti-gB antibodies and some factors such as the age of the animals or the anti-gB antibody titers found at the moment of vaccination.

Table 1. Mean anti-gB antibody titer, variation of anti-gB antibody titers and percentage of animals seropositive against gE in each group throughout the experiment

\begin{tabular}{|c|c|c|c|}
\hline & \multicolumn{3}{|c|}{ Anti-gB antibody titers } \\
\hline & Day $0(08 / 07 / 2014)$ & Day $28(05 / 08 / 2014)$ & Day $56(02 / 09 / 2014)$ \\
\hline Control Group & $2.56+/-0.99$ & $2.72+/-0.90$ & $2.67+/-0.57$ \\
\hline 1 Dose Group & $2.16+/-0.4$ & $3.06+/-0.46$ & $3.42+/-0.43$ \\
\hline \multirow[t]{3}{*}{2 Doses Group } & $2.14+/-0.57$ & $2.9+/-0.76$ & $3.33+/-0.58$ \\
\hline & \multicolumn{3}{|c|}{ Variation of anti-gB antibody titers } \\
\hline & Post-1 ${ }^{\text {st }}$ dose (Day 0-28) & Post- $2^{\text {nd }}$ dose (Day 28-56) & Total (Day 0-56) \\
\hline Control Group & $-215.81+/-1061.14$ & $-809.58+/-990$ & $-1025.4+/-1748.82$ \\
\hline 1 Dose Group & $1580.20+/-1503.58$ & $2021.56+/-3870$ & $3601.76+/-3375.42$ \\
\hline \multirow[t]{3}{*}{2 Doses Group } & $2168.78+/-2836.35$ & $1861.39+/-68.25$ & $4030.17+/-5261$ \\
\hline & \multicolumn{3}{|c|}{ gE seropositivity } \\
\hline & Day $0(08 / 07 / 2014)$ & Day $28(05 / 08 / 2014)$ & Day $56(02 / 09 / 2014)$ \\
\hline Control Group & $3(60 \%)$ & $3(60 \%)$ & $4(80 \%)$ \\
\hline 1 Dose Group & $2(20 \%)$ & $5(50 \%)$ & $7(70 \%)$ \\
\hline 2 Doses Group & $3(30 \%)$ & $2(20 \%)$ & $4(40 \%)$ \\
\hline
\end{tabular}



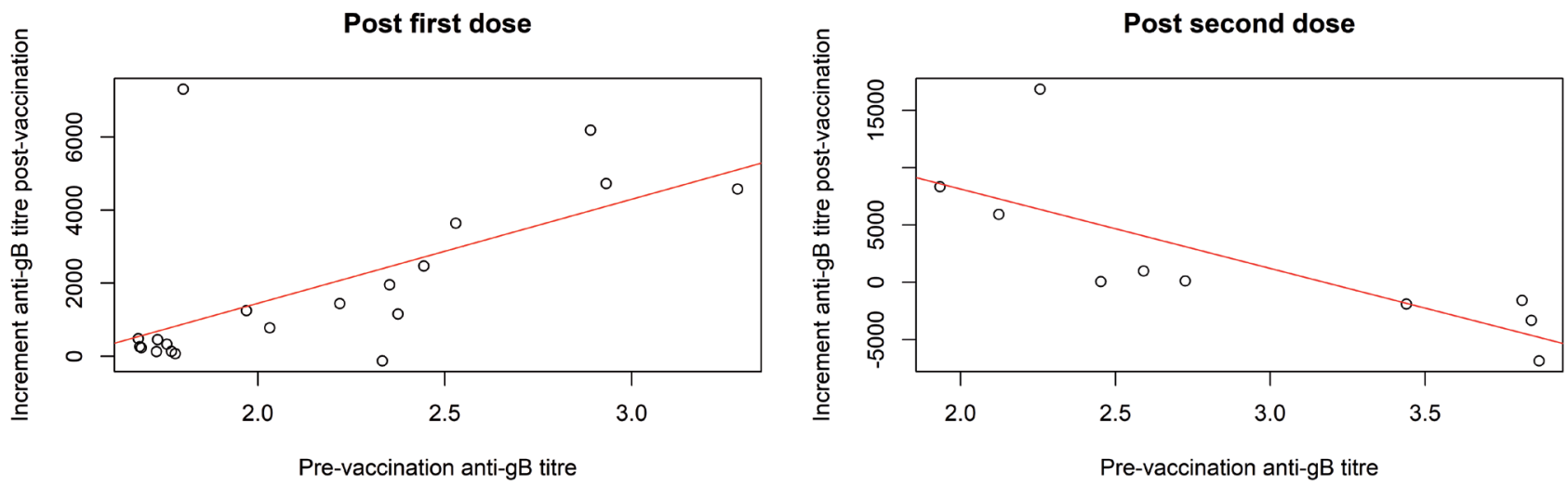

Fig. 1

Correlation between the increment of anti-gB antibody titers and the pre-vaccination anti-gB titer after the first dose (28 days) and the second dose of gE-deleted vaccine against ADV

Finally, a blocking ELISA assay that allowed the detection of antibodies against gE of ADV (present in wild-type strains of ADV but not in vaccine strains) was also carried out. To discard the influence of ADV natural infections in this experiment, we proposed a set of generalized linear models, in which variation of anti-gE antibodies (measured as the variation of ELISA optical density) and group (control, single-dose and revaccinated), were used as variables (alone or in combination) to explain the increment of anti-gB antibody titers (response variable). Among all the possible models, the most parsimonious one was chosen on the basis of AIC criteria (Burnham and Anderson, 2003). An independent set of models was proposed to explain the variation in anti-gB titers for each period of time (post $1^{\text {st }}$ dose, post $2^{\text {nd }}$ dose and total).

Mean anti-gB antibody titers found in each group (control, one dose and two doses) at each time-point and gE seropositivity are summarized in Table 1 . We observed a significant increment of anti-gB antibody titers in singledose group $\left(\mathrm{t}=-15.69, \mathrm{p}=7.6 \times 10^{-8}\right)$ and revaccinated group $(\mathrm{t}=-3.88, \mathrm{p}=0.004)$ after the $1^{\text {st }}$ dose (day $\left.0-28\right)$, but not in the control group $(t=-0.72, p=0.511)$. However, after the $2^{\text {nd }}$ dose (day 28-56), no significant differences in anti$\mathrm{gB}$ antibody titers were found in any of the studied groups. These results suggest that antibody response throughout the experiment was similar in single-dose vaccinated animals and revaccinated ones. Therefore, revaccination did not improve the early antibody response against ADV in wild boar studied.

The serological response after the first dose correlated positively with anti-gB antibody titers at the time of the injection, but not with the age of the animals. This suggests that in animals ranging from 2.5 to 6 months of age, previous contact with ADV or the presence of maternal antibodies, do not reduce the serological effect of $\mathrm{ADV}$ vaccination.

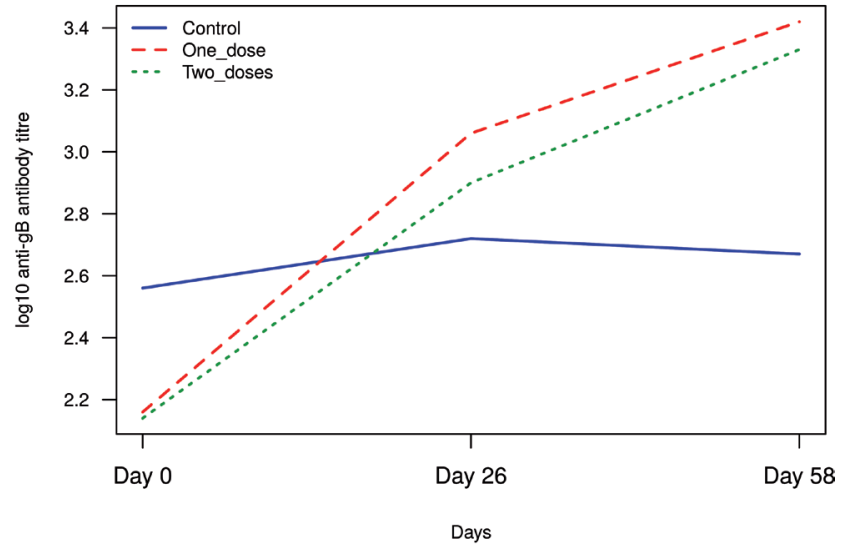

Fig. 2

Evolution of the anti-gB antibody titers of the experimental groups throughout the experiment

Otherwise, after revaccination, the serological response correlated negatively with anti-gB antibody titers at the moment of injection $\left(\beta=-6925, \mathrm{p}=0.09, \mathrm{R}^{2}=0.59\right)$ (Fig. 1). This fact could explain the lack of significant improvement after revaccination, since most of the revaccinated animals had high levels of anti-gB antibodies just before receiving the second dose.

Despite of the significant increment of antibody titers in vaccinated animals, no statistically significant differences were found in anti-gB antibody titers between groups at any time point. It could be explained since at day 0 of the experiment, animals randomly included in the control group showed higher anti-gB antibody titers than vaccinated groups, suggesting the presence of maternal antibodies or previous contact with ADV. These titers remained stable in this group with a moderately high level during the experi- 
Table 2. Model selection to explore the influence of vaccination (group) and gE seropositivity on anti-gB antibody titers of the 25 wild boar studied

\begin{tabular}{lcccc}
\hline Biological models & K & AICc & $\Delta \mathbf{i}$ & $W i$ \\
\hline Post $\mathbf{1}^{\text {st }}$ dose (Day 0 to 28) & & & & \\
Group & 4 & 458.3 & 0.00 & 0.37086 \\
Mo & 2 & 458.8 & 0.50 & 0.28883 \\
Increment gE & 3 & 460.29 & 1.99 & 0.13712 \\
Group + Increment gE & 5 & 460.29 & 1.99 & 0.13712 \\
Group * Increment gE & 7 & 461.75 & 3.45 & 0.06608 \\
\hline Post 2 ${ }^{\text {nd }}$ dose (Day 28 to 56) & & & & \\
Mo & 2 & 499.3 & 0.00 & 0.50592 \\
Increment gE & 3 & 500.42 & 1.12 & 0.28898 \\
Group & 4 & 501.98 & 2.68 & 0.13247 \\
Group + Increment gE & 5 & 503.56 & 4.26 & 0.06012 \\
Group * Increment gE & 7 & 506.7 & 7.40 & 0.01251 \\
\hline Total (Day 0 to 56) & & & & \\
Group & 4 & 491.2879 & 0.00 & 0.35806 \\
Group + Increment gE & 5 & 491.9704 & 0.68 & 0.25453 \\
Increment gE & 3 & 492.4123 & 1.12 & 0.20408 \\
Mo & 2 & 493.0683 & 1.78 & 0.14701 \\
Group * Increment gE & 7 & 495.8642 & 4.58 & 0.03633 \\
\hline K & & & & \\
\hline
\end{tabular}

$\mathrm{K}=$ number of parameters including intercept, $\mathrm{AICc}=$ Akaike Information Criterion corrected for small sample sizes $\triangle \mathrm{AICc}=$ difference of $\mathrm{AICc}$ with respect to the best model, $w i=$ Akaike weight, $\mathrm{Mo}=$ null model only with the constant term.

ment, preventing the observation of significant differences between groups (Fig. 2).

Seropositive animals against $\mathrm{gE}$ were found in all groups at days 0,28 and 56, showing that some of the studied wild boar were naturally infected by ADV during the experiment and/or presented maternal antibodies against ADV. These situations could also raise the level of anti-gB antibodies in affected animals and hence, disguise the effect of vaccination. However, variations in the amount of anti-gE antibodies did not show a correlation with the increment of anti-gB antibody titers, which was positively associated with ADV vaccination instead. In fact, the most parsimonious models to explain anti-gB antibodies variation after the $1^{\text {st }}$ dose (Day 0 to 28) and throughout the experiment (Day 0 to 56) were those including "group" as the only explanatory variable (Table 2). However, after the $2^{\text {nd }}$ dose (day 28-56), the increment in the anti-gB antibody titers was not statistically correlated with any of the explanatory variables proposed (group and anti-gE antibody increment).

This work confirms that vaccination against ADV using gE-deleted vaccine produces a significant antibody response in wild boar. Single-dose vaccinated animals and those that were revaccinated developed a similar antibody response against $\mathrm{ADV}$ in this experiment, suggesting that singledose vaccination programs could be sufficient to produce a serological response in wild boar, at least in the first months of life. Thus, the application of one dose of ADV vaccine in young animals could be explored as a possible measure to reduce $\mathrm{ADV}$ prevalence in wild boar populations.

Acknowledgments. This study was financed by Gobierno de Extremadura (Project reference: EE-140040-4). D. Risco was supported by a Torres Quevedo Grant of the Ministerio de Economía y Competitividad of Spain (PTQ14-06663).

\section{References}

Boadella M, Gortázar C, Vicente J, Ruiz-Fons F (2012): Wild boar: An increasing concern for Aujeszky's disease control in pigs? BMC Vet. Res. 8, 7. https://doi.org/10.1186/17466148-8-7

Bronner A, Rose N, Pol F, Le Potier MF (2010): Bilan de la surveillance de la maladie d'Aujeszky en 2009: renforcement de la surveillance e've'nementielle et alle'gement de la surveillance se' rologique. Bull e' pide' miol Sante' animal aliment 40, 38-41.

Burnham KP, Anderson DR (2003): Model selection and multimodel inference: A practical information-theoretic approach. Springer-Verlag, New York.

Koppel C, Knopf L, Ryser MP, Miserez R, Thür B, and Stärk KDC (2007): Serosurveillance for selected infectious disease agents in wild boars (Sus scrofa) and outdoor pigs in Switzerland. Europ. J. Wildlife Res. 53, 212-220. https:// doi.org/10.1007/s10344-006-0080-0

Maresch C, Lange E, Teifke JP, Fuchs W, Klupp B, Müller T, Mettenleiter TC, and Vahlenkamp TW (2012): Oral immunization of wild boar and domestic pigs with attenuated live vaccine protects against Pseudorabies virus infection. Vet. Microbiol. 161, 20-25. https://doi.org/10.1016/j. vetmic.2012.07.002

Mettenleiter TC, Ehlers B, Müller T, Yoon KJ, and Teifke JP (2012): Herpesviruses. In Zimmerman J, Karriker L, Ramirez A, Schwartz K, Stevenson G (Eds): Diseases of Swine. WileyBlackwell, Ames, Iowa, pp. 421-446.

Müller T, Hahn EC, Tottewitz F, Kramer M, Klupp BG, Mettenleiter TC, and Freuling C (2011): Pseudorabies virus in wild swine: A global perspective. Arch. Virol. 156, 1691-1705. https://doi.org/10.1007/s00705-011-1080-2

Ruiz-Fons F, Rodríguez O, Mateu E, Vidal D, and Gortázar C (2008): Antibody response of wild boar (Sus scrofa) piglets vaccinated against Aujeszky's disease virus. Vet. Rec. 162, 484-485. https://doi.org/10.1136/vr.162.15.484 